\title{
Correlation of Risk Factor of Pressure Ulcer Using the Braden Risk Assessment Scale
}

\author{
(D) Cansu Berktaş Kılınç, (D) Mehmet Zincirci, (1) ibrahim Gün, (D) Namigar Turgut, (1) Serap Karacalar, (D) Nagihan Duran Yakar, \\ (D) Tarkan Mıngır, (1D Nihan Altıntepe
}

University of Health Sciences Turkey, Prof. Dr. Cemil Taş̧̧ığlu City Hospital, Clinic of Anesthesiology and Reanimation, Istanbul, Turkey

\section{Abstract}

Objective: Pressure ulcers (PUs) are a common problem in intensive care units (ICUs) and lead to prolonged hospital stay and increased mortality and treatment cost. The Norton and Braden Risk Assessment scales (BRAS) were developed for this purpose. However, in recent years, it has been suggested that BRAS is insufficient.

This study aimed to investigate the correlation between BRAS and risk factors of PU in patients treated in the ICU.

Methods: This retrospective, single-center study was conducted between February and July 2017 and enrolled 200 patients with standardized $\mathrm{PaO}_{2} / \mathrm{FiO}_{2}$ ratio and BRAS scores, and all possible risk factors including age, sex, serum hemoglobin $(\mathrm{Hb})$, albumin, bilirubin, creatinine, platelet, mechanical ventilation support, Glasgow Coma scale (GCS) scores, Nutritional Risk Screening (NRS2002) scores, Acute Physiology and Chronic Health Evaluation (APACHE) 2 scores, hypotension, and expected mortality were evaluated.

Results: The ages of the patients included the study were between 18 and 95 years, with a mean age of $62.84 \pm 17.98$ years [88 (44\%) women and $112(56 \%)$ men]. A positive correlation was noted between BRAS measurements and albumin, $\mathrm{Hb}$, GCS, hypotension, and $\mathrm{PaO}_{2} / \mathrm{FiO}_{2}$ measurements. Also, a negative correlation was noted between BRAS measurements and NRS2002 values, direct bilirubin levels, APACHE 2, and expected mortality values.

Conclusion: Low albumin and $\mathrm{Hb}$ values, GCS, and $\mathrm{PaO}_{2} / \mathrm{FiO}_{2}$ values, hypotension, and high indirect bilirubin levels, NRS2002, and APACHE 2 scores are risk factors for developing PU. It is inferred from our study that these symptoms and standard laboratory results should be used as additional indicators in determining the risk of PU, and BRAS should be modified by considering these risk factors.

Keywords: Braden Risk Assessment scale, pressure ulcer, albumin

\section{INTRODUCTION}

Pressure ulcers (PUs) are localized tissue injuries of the skin and subcutaneous tissues covering bone protrusions and usually result from factors such as pressure, friction, tear, and others (1). It is a common problem in intensive care units (ICUs) and leads to prolonged hospital stay and increased mortality and treatment cost (2). The success of preventive intervention and treatment methods depends on thoroughly understanding etiological methods. However, the multiplicity of risk factors and differences in the results of the study on the subject impedes a complete consensus on the prevention and treatment of PU (3). Hence, it is necessary to define the presence of predisposing factors in the etiology of PU in such an important tissue. For this purpose, several scales have been developed, and the Norton and Braden Risk Assessment scales (BRAS) are the most important ones. The Norton Scale is the simplest and evaluates mental state, activity, mobility, and incontinence. The BRAS has a more detailed questioning and risk rating. However, it has low calibration power in predicting the risk of PU development. 
Additionally, it cannot predict serum albumin levels because of malnutrition, which is an important part of predisposing factors (4-7).

Our study aimed to investigate the validity and reliability of BRAS in determining the risk groups in patients treated in the ICU.

\section{METHODS}

This retrospective, single-center study was conducted between February and July 2017 and enrolled 200 patients. When patients were admitted in the ICU, demographic data (age and sex) and initial values of BRAS, hemoglobin $(\mathrm{Hb})$, serum albumin, bilirubin (direct and indirect), creatinine, platelet, Glasgow Coma scale (GCS), Nutritional Risk Screening (NRS2002), Sequential Organ Failure Assessment (SOFA), and Acute Physiology and Chronic Health Evaluation (APACHE) 2 were recorded. If the patient is given mechanical ventilation support, the first $\mathrm{PaO}_{2} / \mathrm{FiO}_{2}$ ratio, hypotension, and expected mortality were evaluated.

\section{Statistical Analysis}

Statistical analysis was conducted using the Number Cruncher Statistical System 2007 (Kaysville, UT, USA) program. Student's t-test was used to compare descriptive statistical methods (mean, standard deviation, median, frequency, ratio, minimum, and maximum) and two groups of variables that showed normal distribution in the comparison of quantitative data. The Kruskal-Wallis test was used to compare groups of three and more with no normal distribution, and the Mann-Whitney $\mathrm{U}$ test was used to determine the group that caused the difference. Pearson and Spearman correlation analyses were used to evaluate the relationships between variables. Significance was evaluated at $p<0.05$ levels.

\section{RESULTS}

The ages of the patients included the study were between 18 and 95 years, with a mean age of $62.84 \pm 17.98$ years. There were 88 (44\%) female and 112 (56\%) male patients (Table 1). The distributions of the descriptive characteristics of the cases are shown in Table 2.

There was no statistically significant relationship between BRAS measurements and age distributions, indirect bilirubin, creatinine, and platelet count ( $p>0.05)$. A significant correlation was noted between BRAS and serum albumin measurements (the albumin levels increased as the BRAS values increased), and $31.5 \%$ relationship was statistically significant $(r=0.315$, $p=0.001$ ). There was also a positive correlation between BRAS measurements and $\mathrm{Hb}$ levels (the $\mathrm{Hb}$ levels increased as the BRAS values increased). The statistical significance of the relationship has been found weak ( $r=0.198, p=0.005)$. A positive correlation between BRAS measurements and GCS values was found (the GCS values increased as the BRAS values increased), and $62.6 \%$ relationship was statistically significant $(r=0.626, p=0.00)$. There was a positive relationship between BRAS and hypotension

\begin{tabular}{|c|c|c|c|}
\hline & & $\begin{array}{l}\text { Minimum-maximum } \\
\text { (median) }\end{array}$ & Mean \pm SD \\
\hline \multicolumn{2}{|c|}{ Age (year) } & $13-95(66)$ & $62.84 \pm 17.98$ \\
\hline \multicolumn{2}{|l|}{ GCS } & $3-15(14)$ & $12.36 \pm 3.38$ \\
\hline & & $\mathbf{n}$ & $\%$ \\
\hline \multirow{2}{*}{ Gender } & Female & 88 & 44.0 \\
\hline & Male & 112 & 56.0 \\
\hline
\end{tabular}

\begin{tabular}{|c|c|c|c|}
\hline & \multicolumn{2}{|c|}{$\begin{array}{l}\text { Minimum-maximum } \\
\text { (median) }\end{array}$} & Mean \pm SD \\
\hline Albumin & \multicolumn{2}{|c|}{$0.20-4.60(3)$} & $2.98 \pm 0.81$ \\
\hline Direct bilirubin & \multicolumn{2}{|c|}{$0.01-4.72(0.21)$} & $0.47 \pm 0.72$ \\
\hline Indirect bilirubin & \multicolumn{2}{|l|}{$0-2.46$} & $0.35 \pm 0.32$ \\
\hline Creatinine & \multicolumn{2}{|c|}{$0.15-6.40(0.88)$} & $1.16 \pm 0.97$ \\
\hline Platelet count $\left(x 10^{3}\right)$ & \multicolumn{2}{|c|}{$10-979(230)$} & $249.16 \pm 133.75$ \\
\hline $\mathrm{Hb}$ & \multicolumn{2}{|c|}{$2.50-18(10.8)$} & $10.99 \pm 2.13$ \\
\hline NRS2002 & \multicolumn{2}{|l|}{$0-6(3)$} & $2.54 \pm 1.51$ \\
\hline APACHE 2 & \multicolumn{2}{|c|}{ 3-49 (12) } & $15.13 \pm 9.16$ \\
\hline Expected mortality (\%) & \multicolumn{2}{|c|}{ 4-97 (15) } & $26.13 \pm 23.22$ \\
\hline BRDs & \multicolumn{2}{|c|}{$9-23(19)$} & $17.98 \pm 3.30$ \\
\hline Hypotension & \multicolumn{2}{|c|}{$11-160(91)$} & $90.67 \pm 21.63$ \\
\hline \multirow[t]{2}{*}{$\mathrm{PaO}_{2} / \mathrm{FiO}_{2}$} & \multicolumn{2}{|c|}{$88-660$ (311) } & $321.91 \pm 134.03$ \\
\hline & & $\mathbf{n}$ & $\%$ \\
\hline \multirow{2}{*}{ Mechanical ventilation } & $(-)$ & 154 & 77.0 \\
\hline & $(+)$ & 46 & 23.0 \\
\hline \multirow{5}{*}{ SOFA score } & $0-6$ & 164 & 82.0 \\
\hline & $7-9$ & 21 & 10.5 \\
\hline & $10-12$ & 11 & 5.5 \\
\hline & $13-14$ & 3 & 1.5 \\
\hline & 15 & 1 & 0.5 \\
\hline \multirow{5}{*}{ Expected mortality (\%) } & $0-20$ & 165 & 82.5 \\
\hline & $20-40$ & 20 & 10.0 \\
\hline & $40-60$ & 12 & 6.0 \\
\hline & $60-80$ & 2 & 1.0 \\
\hline & $80-100$ & 1 & 0.5 \\
\hline
\end{tabular}


measurements (increased hypotension values were observed as the BRAS measurements increased). About 27.5\% relationship was found to be statistically significant $(r=0.275, p=0.01)$. BRAS measurements were positively correlated with $\mathrm{PaO}_{2} / \mathrm{FiO}_{2}$ measurements (the increased $\mathrm{PaO}_{2} / \mathrm{FiO}_{2}$ values were noted as the BRAS values increased), and $45.2 \%$ relationship was found to be statistically significant $(r=0.452 ; p=0.001)$. There was a negative correlation between BRAS measurements and NRS2002 values (decreased NRS2002 values were measured as the BRAS values increased). The correlation was statistically significant $(r=0.450$, $p=0.001)$. BRAS measurements were negatively correlated with direct bilirubin levels (the direct bilirubin levels decreased as the BRAS values increased), and $27 \%$ relationship was found to be statistically significant $(r=-0.270 ; p=0.001)$. BRAS measurements were negatively correlated with APACHE 2 and expected mortality values (decreased APACHE 2 and expected mortality values were noted as the BRAS values increased). A 61.9\% relationship was statistically significant ( $r=-0.619 ; p=0.001$; Table 3, Figure 1).

There was no statistically significant difference between BRAS measurements of the cases according to gender $(p>0.05)$. The BRAS measurements of non-intubated patients were significantly higher than intubated ones $(p=0.001)$. A statistically significant difference was found between the BRAS measurements of the patients according to SOFA score $(p=0.001)$. According to the results of the Mann-Whitney $U$ test performed to determine the differences, the BRAS values of patients with SOFA scores between 0 and 6 were significantly higher than those with SOFA scores of 7-9 and 10-12 ( $p=0.001$ for each). Similarly,
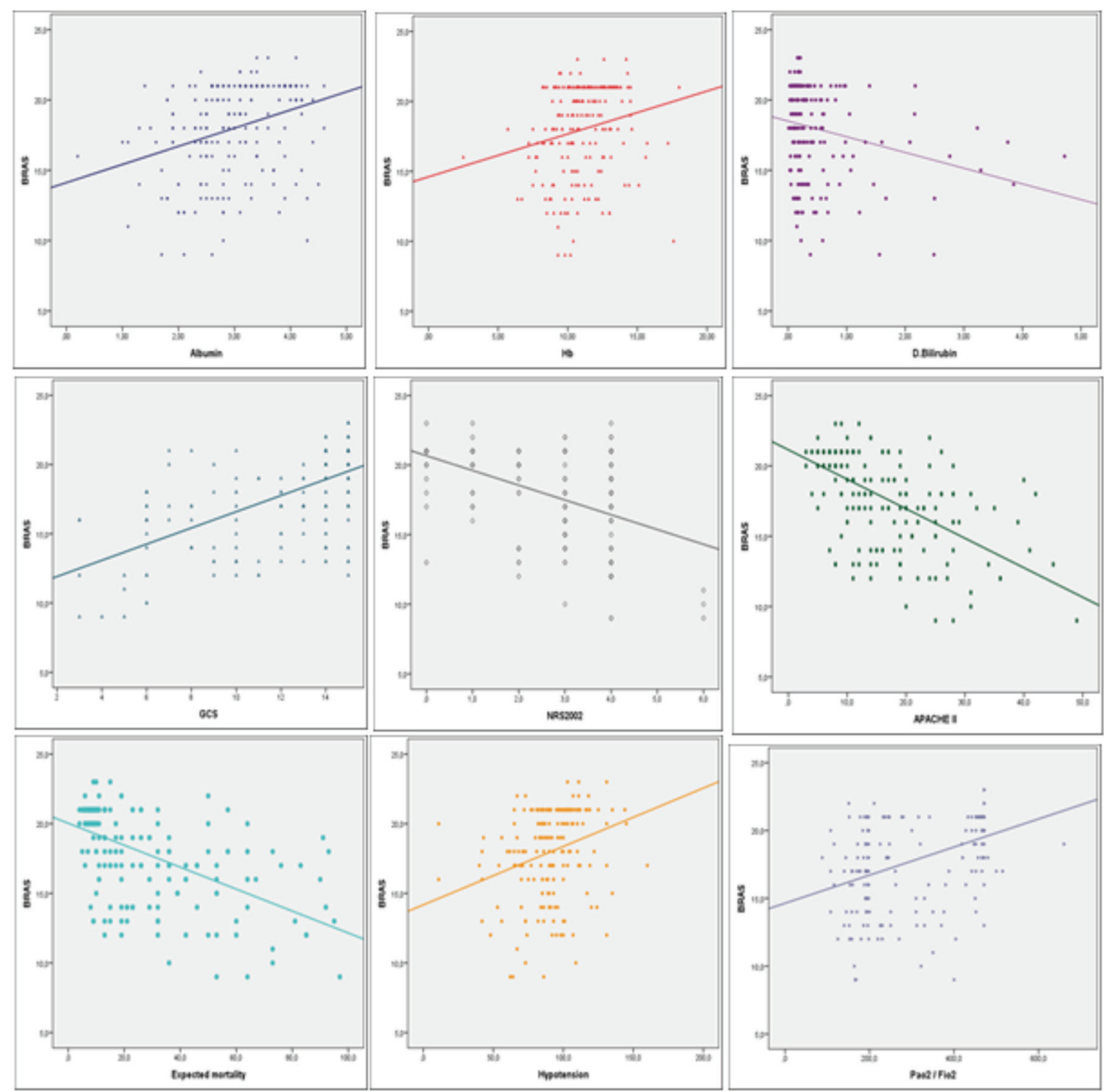

Figure 1. The correlation between BRAS measurements and albumin, Hb, direct biluribin, GCS, NRS2002, APACHE 2, expected mortality, hypotension, and $\mathrm{PaO}_{2} / \mathrm{FiO}_{2}$ ratio

BRAS: Braden Risk Assessment scale, Hb: Hemoglobin, GCS: Glasgow Coma scale, NRS2002: Nutritional Risk Screening, APACHE 2: Acute Physiology and Chronic Health Evaluation 2 
the BRAS values of patients with SOFA scores between 7 and 9 were significantly higher than those with SOFA scores between 10 and $12(p=0.049)$. A statistically significant difference was found between the BRAS measurements of the cases according to mortality. According to the results of the Mann-Whitney $U$ test performed to determine the difference, the BRAS values of

\begin{tabular}{|c|c|c|}
\hline \multicolumn{3}{|c|}{$\begin{array}{l}\text { Table } 3 \text {. Evaluation of the relatoinship } b \\
\text { other variables } \\
\\
\end{array}$} \\
\hline & $r$ & p \\
\hline Age & -0.124 & $0.080^{\mathrm{a}}$ \\
\hline Albumin & 0.315 & $0.001^{\mathrm{a}^{*}}$ \\
\hline Direct bilirubin & -0.270 & $0.001^{b^{*}}$ \\
\hline Indirect bilirubin & -0.004 & $0.951^{b}$ \\
\hline Creatinine & -0.125 & $0.077^{b}$ \\
\hline Platelet count (x103) & -0.024 & $0.733^{\mathrm{a}}$ \\
\hline $\mathrm{Hb}$ & 0.198 & $0.005^{\mathrm{a}^{*}}$ \\
\hline GCS & 0.626 & $0.001^{b^{*}}$ \\
\hline NRS2002 & -0.450 & $0.001^{b^{*}}$ \\
\hline APACHE 2 & -0.619 & $0.001^{b^{*}}$ \\
\hline Expected mortality & -0.619 & $0.001^{b^{*}}$ \\
\hline Hypotension & 0.275 & $0.001^{\mathrm{a}^{*}}$ \\
\hline $\mathrm{PaO}_{2} / \mathrm{FiO}_{2}$ & 0.452 & $0.001^{b^{*}}$ \\
\hline \multicolumn{3}{|c|}{$\begin{array}{l}{ }^{a} \text { r: Pearson correlation coefficient, }{ }^{b} r \text { : Spearman's correlation coefficient, }{ }^{*} p<0.01 \text {, } \\
\text { BRAS: Braden Risk Assessment scale, Hb: Hemoglobin, GCS: Glasgow Coma score; } \\
\text { NRS2002: Nutritional Risk Screening, SOFA: Sequential Organ Failure Assessment, } \\
\text { APACHE 2: Acute Physiology and Chronic Health Evaluation } 2\end{array}$} \\
\hline
\end{tabular}

patients with an expected mortality of $0-20 \%$ were significantly higher than those with expected mortality of between $20-40 \%$ and $40-60 \%$ ( $p=0.001$ for each, Table 4$)$.

\section{DISCUSSION}

In 1997, the first reliability and validity study of the scale developed by Braden and Bergstrom was conducted by Oguz in Turkey. In 1998, Pınar and Oğuz (8) examined the reliability and safety of the Norton Risk Assessment scale and BRAS. The reliability and validity of the scales were high in both studies and other studies (8-10). The scale includes six subdimensions, including sensory perception, moisture, activity, movement, nutrition, and friction and shear (11).

The total score of the scale is obtained by collecting the subdimension score. The values ranged from 6 to 23. Based on the total score, 12 points and below indicate high risk, 13-14 points indicate risk, 15-16 points indicate low risk, and 15-18 points indicate low risk in patients older than 75 years $(7,9)$.

According to Karadağ (12), BRAS is the most reliable and valid scale for patients in the wide age range and is currently the most widely used scale in the United States. Balzer et al. (13) reported that it is the risk assessment tool with the best sensitivityspecificity balance. It is recommended for use in intensive care and long-term care units, but the subdimensions of the perception of moisture, nutrition, and stimulus should be more

\begin{tabular}{|c|c|c|c|c|}
\hline & & \multicolumn{2}{|l|}{ BRAS } & \multirow{2}{*}{\begin{tabular}{|l} 
Test value \\
$\mathbf{p}$
\end{tabular}} \\
\hline & & Minimum-maximum (median) & Mean \pm SD & \\
\hline \multirow{2}{*}{ Gender } & Female $(\mathrm{n}=88)$ & $9-23(19)$ & $18.07 \pm 3.26$ & $\mathrm{t}: 0.353$ \\
\hline & Male $(n=112)$ & 9-23 (18) & $17.9 \pm 3.34$ & $0.724^{a}$ \\
\hline \multirow{2}{*}{ Intubation } & No $(n=154)$ & $12-23(20)$ & $18.81 \pm 2.84$ & t: 7.397 \\
\hline & Yes $(n=46)$ & $9-21(16)$ & $15.17 \pm 3.20$ & $0.001^{\mathrm{a}^{* *}}$ \\
\hline \multirow{5}{*}{ SOFA score } & $0-6(n=164)^{1}$ & $12-23(20)$ & $18.63 \pm 2.96$ & $\chi^{2}: 30.895$ \\
\hline & $7-9(n=21)^{2}$ & $10-20(17)$ & $16.00 \pm 2.66$ & $0.001^{b^{* *}}$ \\
\hline & $10-12(n=11)^{3}$ & 9-18 (14) & $13.64 \pm 3.38$ & $\mathrm{p}=0.001^{1,2^{* *}}$ \\
\hline & $13-14(n=3)^{\#}$ & $13-17(14)$ & $14.67 \pm 2.08$ & $\mathrm{p}=0.001^{1,3^{* *}}$ \\
\hline & $15(n=1)^{\#}$ & $9-9(9)$ & $9.00 \pm 0.00$ & $\mathrm{p}=0.049^{2,3^{*}}$ \\
\hline \multirow{5}{*}{ Expected mortality (\%) } & $0-20(n=165)$ & $12-23(20)$ & $18.62 \pm 2.95$ & $\chi^{2}: 30.482$ \\
\hline & $20-40(n=20)$ & $10-20(16.5)$ & $15.95 \pm 2.72$ & $0.00^{\mathrm{b}^{* *}}$ \\
\hline & $40-60(n=12)$ & 9-18 (15) & $13.92 \pm 3.37$ & $\mathrm{p}=0.001^{1,2^{* *}}$ \\
\hline & $60-80(n=2)^{\#}$ & $13-14(13.5)$ & $13.5 \pm 0.71$ & $p=0.001^{1,3^{* *}}$ \\
\hline & $80-100(n=1)^{\#}$ & 9-9 (9) & $9.00 \pm 0.00$ & $\mathrm{p}=0.084^{2,3}$ \\
\hline
\end{tabular}


clearly defined $(14,15)$. In the study of Kottner and Dassen (16) in patients in the ICU, BRAS is a more reliable risk measurement tool than the Waterlow scale, but using these scales coexistencely is recommended. BRAS is the most widely used scale and has also been used in many studies conducted in our country $(3,17-$ 19).

Previous studies have shown that patients categorized as high risk according to BRAS have a higher incidence of pressure sores. However, BRAS can be used to determine the risk of developing PU in hospitalized patients, although it may be insufficient for risk assessment in patients in the ICU $(19,20)$. In a retrospective study conducted by Sardo et al. (21), PU developed in 153 (2.3\%) of 6.652 patients, and other than nutrition, assessment factors such as mobility and activity were accepted as independent risk factors for developing PU. In our study, there was a positive correlation between BRAS measurements and serum albumin levels (the albumin levels increased as the BRAS values increased). A 31.5\% relationship was found to be statistically significant. However, Kurtuluş and Pınar (22) showed that 18.3\% of pressure wound incidences are noteworthy despite hypoalbuminemia.

Hypoalbuminemia, which is widely accepted as a risk factor for PU development, seems to have lost its importance against conditions such as changing position every $2 \mathrm{~h}$, assessing the skin every position change, preventing excessive humidity, pressure, and irritation of the sheets and clothes, and using pressurereducing devices (23). Increased risk of PU is related to factors such as previous stroke, trauma, cognitive function decline, poor GCS, and delayed enteral nutrition. It has been shown that there was a significant correlation between PU and 21-day mortality and 3-month recovery in patients with traumatic cerebral injury. Hence, early nutritional support and $\mathrm{Hb}$ level monitoring should be considered important parts of nursing care interventions in patients with high risk of developing PU $(23,24)$. In our study, there was a positive correlation between BRAS measurements and $\mathrm{Hb}$ levels (the $\mathrm{Hb}$ levels increased as the BRAS values increased). A weak $19.8 \%$ relationship was found. BRAS measurements were significantly correlated with GCS values (the GCS values increased as the BRAS measurements increased). A $62.6 \%$ relationship was found to be statistically significant.

The retrospective study by El-Marsi et al. (25) has been conducted in a university hospital with 420 bed capacity and included 145 patients with newly developed PU. Variables such as gender, age, inotropic agent usage, primary disease, comorbidity, and weight (entry and exit weights in the ICU) were compared with BRAS measurements. The length of ICU stay, use of vasopressors, and duration of hypotension were found as prominent factors in the development of PU. In our study, a 27.5\% positive relationship between BRAS measurements and hypotension levels was significant. There was also a $45.2 \%$ positive and statistically significant relationship between BRAS measurements and $\mathrm{PaO}_{2} /$ $\mathrm{FiO}_{2}$ values (the $\mathrm{PaO}_{2} / \mathrm{FiO}_{2}$ values increased as the BRAS values increased) $(r=0.452 ; p=0.001 ; p<0.01)$.

\section{CONCLUSION}

BRAS can be eligible in determining the risk of developing $\mathrm{PU}$ in hospitalized patients but is insufficient in determining the risk of critical patients in the ICU. Low albumin and $\mathrm{Hb}$ values, $\mathrm{GCS}, \mathrm{PaO}_{2} / \mathrm{FiO}_{2}$ values, hypotension, and high indirect bilirubin levels, NRS2002, and APACHE 2 score are risk factors for developing PU.

It is inferred from our study that these symptoms and standard laboratory results should be used as additional indicators in determining the risk of PU, and BRAS should be modified by considering these risk factors.

\section{Ethics}

Ethics Committee Approval: Retrospective study.

Informed Consent: Retrospective study.

Peer-review: Externally and internally peer-reviewed.

\section{Authorship Contributions}

Surgical and Medical Practices: C.B.K., M.Z., I.G., N.T., S.K., N.D.Y, T.M., N.A., Concept: C.B.K., M.Z., N.T., Design: C.B.K., M.Z., N.T., Data Collection or Processing: C.B.K., M.Z., I.G., N.D.Y., T.M., N.A., Analysis or Interpretation: C.B.K., N.T., S.K., N.A., Literature Search: C.B.K., M.Z., I.G., N.D.Y., T.M., N.A., Writing: C.B.K., M.Z., N.T., S.K., T.M.

Conflict of Interest: No conflict of interest was declared by the authors.

Financial Disclosure: The authors declared that this study received no financial support.

\section{REFERENCES}

1. European Pressure Ulcer Advisory Panel and National Pressure Ulcer Advisory Panel. Treatment of pressure ulcers: Quick Reference Guide [online] 2009

2. Toptas M, Sengul Samanci N, Akkoc I, Yucetas E, Cebeci E, Sen O, et al. Factors Affecting the Length of Stay in the Intensive Care Unit: Our Clinical Experience. Biomed Res Int 2018;2018:943046.

3. Sivrioğlu K, Özcan O. Basınç Ülserleri. Ed: Özcan O, Arpacıoğlu O, Turan B. Nörorehabilitasyon, Bursa; 2000. p.276-91. 
4. Turgut N, Ak A, Ak E, Yakar N, Yakar N, Yılmaz B, et al. Incidence, Prevention and Treatment of Pressure Ulcers in Intensive Care Patients. J Turk Soc Intensive 2017;15:72-6.

5. Chen HL, Cao YJ, Wang J, Huai BS. Calibration power of the Braden scale in predicting pressure ulcer development. J Wound Care 2016;25:655-9.

6. Serpa LF, Santos VL. Validity of the Braden Nutrition Subscale in predicting pressure ulcer development. J Wound Ostomy Continence Nurs 2014;41:436-43.

7. Hyun S, Vermillion B, Newton C, Fall M, Li X, Kaewprag P, et al. Predictive validity of the Braden scale for patients in intensive care units. Am J Crit Care 2013;22:514-20.

8. Pınar R, Oğuz S. Norton ve Braden Bası Yarası Değerlendirme Ölçeklerinin Yatağa Bağımlı Aynı Hasta Grubunda Güvenirlik ve Geçerliğinin Sınanması: Uluslararası Katılımlı VI. Ulusal Hemșirelik Kongresi, Kongre Kitabı, Ankara; 1998.p.172-5.

9. Fırat Kılıç H, Sucu Dağ G. The scales frequently used in the assessment of pressure sores. JAREN 2017;3:49-54.

10. Bergstrom N, Braden BJ, Laguzza A, Holman V. The Braden Scale for Predicting Pressure Sore Risk. Nurs Res 1987;36:205-10.

11. Stoelting J, McKenna L, Taggart E, Mottar R, Jeffers BR, Wendler MC. Prevention of nosocomial pressure ulcers: a process improvement project. J Wound Ostomy Continence Nurs 2007;34:382-8.

12. Karadağ A. Basınç ülserleri: Değerlendirme, önleme ve tedavi. C.Ü. Hemşirelik Yüksek Okulu 2003;7:41-8.

13. Balzer K, Pohl C, Dassen T, Halfens R. The Norton, Waterlow, Braden, and Care Dependency Scales: comparing their validity when identifying patients' pressure sore risk. J Wound Ostomy Continence Nurs 2007;34:389-98.

14. Kottner J, Dassen T, Tannen A. Inter- and intrarater reliability of the Waterlow pressure sore risk scale: a systematic review. Int J Nurs Stud 2009;46:369-79.

15. Fernandes LM, Caliri MH. Using the Braden and Glasgow scales to predict pressure ulcer risk in patients hospitalized at intensive care units. Rev Lat Am Enfermagem 2008;16:973-8.
16. Kottner J, Dassen T. Pressure ulcer risk assessment in critical care: interrater reliability and validity studies of the Braden and Waterlow scales and subjective ratings in two intensive care units. Int J Nurs Stud 2010;47:671-7.

17. Jun Seongsook RN, Jeong Ihnsook RN, Lee Younghee RN. Validity of pressure ulcer risk assessment scales; Cubbin and Jackson, Braden, and Douglas scale. Int J Nurs Stud 2004;41:199-204.

18. Magnan MA, Maklebust J. Braden Scale risk assessments and pressure ulcer prevention planning: what's the connection? J Wound Ostomy Continence Nurs 2009;36:622-34.

19. Sönmez Düzkaya D, Terzi B, Yakut T, Kızıl N. Where We are on Pressure Ulcers?: Data of Last Year in Pediatric Intensive Care Unit. Anadolu Hemşirelik ve Sağıık Bilimleri Dergisi 2014;17:4.

20. Serpa LF, Santos VL, Campanili TC, Queiroz M. Predictive validity of the Braden scale for pressure ulcer risk in critical care patients. Rev Lat Am Enfermagem 2011;19:50-7.

21. Sardo PMG, Guedes JAD, Alvarelhão JJM, Machado PAP, Melo EMOP. Pressure ulcer incidence and Braden subscales: Retrospective cohort analysis in general wards of a Portuguese hospital. J Tissue Viability 2018;27:95-100.

22. Kurtuluş Z, Pınar R. Relation between albumin levels and pressure sore in high-risk patients defined with Braden's Risk Assessment tool. C.Ü. Hemșirelik Yüksek Okulu 2003;7:1-10.

23. Dhandapani M, Dhandapani S, Agarwal M, Mahapatra AK. Pressure ulcer in patients with severe traumatic brain injury: significant factors and association with neurological outcome. J Clin Nurs 2014;23:1114-9.

24. Capon A, Pavoni N, Mastromattei A, Di Lallo D. Pressure ulcer risk in longterm units: prevalence and associated factors. J Adv Nurs 2007;58:26372.

25. El-Marsi J, Zein-El-Dine S, Zein B, Doumit R, Kurdahi Badr L. Predictors of Pressure Injuries in a Critical Care Unit in Lebanon: Prevalence, Characteristics, and Associated Factors. J Wound Ostomy Continence Nurs 2018;45:131-6. 